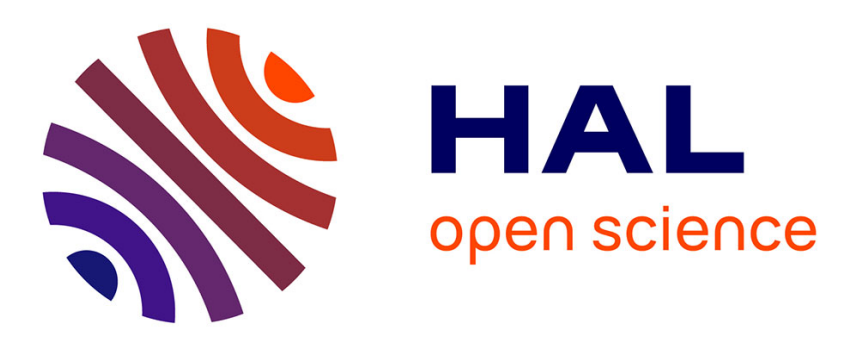

\title{
Age and environmental conditions affect recruitment in Greater Snow Geese
}

Eric T Reed, Gilles Gauthier, Roger Pradel, Jean-Dominique Lebreton

\section{To cite this version:}

Eric T Reed, Gilles Gauthier, Roger Pradel, Jean-Dominique Lebreton. Age and environmental conditions affect recruitment in Greater Snow Geese. Ecology, 2003, 84 (1), pp.219 - 230. 10.1890/00129658(2003)084[0219:AAECAR]2.0.CO;2 . hal-02126384

\section{HAL Id: hal-02126384 \\ https://hal.science/hal-02126384}

Submitted on 11 May 2019

HAL is a multi-disciplinary open access archive for the deposit and dissemination of scientific research documents, whether they are published or not. The documents may come from teaching and research institutions in France or abroad, or from public or private research centers.
L'archive ouverte pluridisciplinaire HAL, est destinée au dépôt et à la diffusion de documents scientifiques de niveau recherche, publiés ou non, émanant des établissements d'enseignement et de recherche français ou étrangers, des laboratoires publics ou privés. 


\title{
AGE AND ENVIRONMENTAL CONDITIONS AFFECT RECRUITMENT IN GREATER SNOW GEESE
}

\author{
Eric T. Reed, ${ }^{1,3}$ Gilles Gauthier, ${ }^{1}$ Roger Pradel, ${ }^{2}$ and Jean-Dominique Lebreton ${ }^{2}$ \\ ${ }^{1}$ Département de Biologie and Centre d'Études Nordiques, Pavillon Vachon, Université Laval, Sainte-Foy, \\ Québec, Canada G1K 7P4 \\ ${ }^{2}$ Centre d'Écologie Fonctionnelle et Évolutive-CNRS, 1919 Rte. De Mende, 34293 Montpellier, Cedex 5, France
}

\begin{abstract}
Recruitment is an important determinant of fitness and population growth rates, but few studies have examined the effect of environmental stochasticity on this life history trait. Furthermore, most studies have been unable to separate the influence of juvenile survival and age-specific breeding proportions on recruitment. We used a recently developed approach, based on capture-mark-recapture methods, in which local recruitment is analyzed in a multistate model with an unobservable "nonbreeder" state. The data are drawn from a long-term study of a long-lived, arctic-nesting bird, the Greater Snow Goose (Chen caerulescens atlantica), and include marking and recaptures of female goslings and breeding adult females of unknown age between 1990 and 2000. The model considers four parameters: the probability that an individual aged $i$ with no breeding experience starts breeding $\left(a_{i}\right)$, juvenile and adult apparent survival $(\Phi)$, and capture probability of breeders $(p)$. The flexibility achieved allows us to assess the influence of environmental conditions encountered during early life and at breeding on juvenile survival and the probabilities of starting to breed at a given age. Recruitment was a gradual process (probability of starting to breed at age $2 \mathrm{yr}=0.25$ [95\% CI, 0.12-0.45]; at age $3 \mathrm{yr}=0.57[0.20-0.87]$ ) and was completed by age 4 yr (i.e., all remaining immature females started to breed at that age). Juvenile survival was higher in early-hatched than in late-hatched females. Juvenile survival varied considerably among cohorts, but our environmental covariates could not explain these differences. Probabilities of starting to breed were less variable, except in lemming crash years, when they were considerably reduced. Snow cover at breeding or hatch date did not affect probabilities of starting to breed. These results suggest that environmental conditions can have an impact on life histories of birds in seasonal environments, but that variations in juvenile survival probably account for most of the fluctuation in the proportion of birds from a cohort that recruit into the breeding population. Use of multistate models to estimate recruitment increases precision in parameter estimates with the addition of data from adults of unknown age. However, we are still restricted by some assumptions, most notably the absence of temporary emigration.
\end{abstract}

Key words: age-specific breeding probability; breeding propensity; capture-mark-recapture models; Chen caerulescens atlantica; environmental stochasticity; Greater Snow Goose; local recruitment; maturity; multistate models; population dynamics; reproduction; survival.

\section{INTRODUCTION}

Recruitment, defined as the establishment of new individuals in the breeding segment of populations, is an essential component of population dynamics. The probability of recruitment into the population is a threestage process: survival from hatching to fledging (or weaning in mammals), survival from fledging to age of sexual maturity, and age of first breeding (age at maturity). At the individual level, age at first breeding may be an important determinant of fitness (Gadgil and Bossert 1970), whereas at the population level it may

Manuscript received 26 November 2001; revised 20 May 2002; accepted 27 May 2002. Corresponding Editor: T. D. Williams.

${ }^{3}$ Present address: Canadian Wildlife Service, Migratory Birds Conservation Division, Place Vincent Massey, 351 St. Joseph Blvd., Hull, Québec K1A 0H3, Canada.

E-mail: eric.reed@ec.gc.ca have a major impact on population growth rates (Porter and Coulson 1987, Gaillard et al. 1998). Delayed accession to reproduction is common in long-lived species, often exceeding the age at which reproduction is physiologically possible (Bell 1980).

Poor environmental conditions at birth or at breeding may restrain or constrain early reproduction by reducing potential benefits of an early breeding attempt $(\mathrm{Cu}-$ rio 1983, Cam et al. 1998). Although numerous studies have addressed the influence of environmental stochasticity on different life history traits (e.g., Boyce and Perrins 1987, Sedinger et al. 1995), very few have studied the impact of environmental conditions encountered at birth or at breeding on recruitment.

In seasonal environments, hatch date may be an important determinant of fitness. Even though accession to reproduction may not occur for several years, the date when an individual hatches from its egg may still influence the circumstances that determine recruitment. 
Individual hatch date influences survival and age of first breeding across a variety of bird species (e.g., Spear and Nur 1994, Verboven and Visser 1998, Prévot-Julliard et al. 2001). Hatch date is negatively related to recruitment in geese (Cooke et al. 1984, Sedinger et al. 1995) and ducks (Dawson and Clark 2000), but it is not clear whether this is an effect of hatch date on juvenile survival (Owen and Black 1989, Cooch et al. 1993, Schmutz 1993, Lepage et al. 2000) or on age of first breeding. Environmental conditions at the start of the breeding season may affect recruitment if they result in delayed nesting (Prop and de Vries 1993, Lepage et al. 1996), restricted access to feeding (Gauthier and Tardif 1991, Choinière and Gauthier 1995, Ganter and Cooke 1996), or generally reduce breeding effort and success (Barry 1962, Skinner et al. 1998). Predator abundance and activity at the colonies during the prebreeding period can also induce birds to forego breeding (Spaans et al. 1998).

Environmental influence on recruitment has rarely been studied in long-lived species because of the difficulty of estimating this life history trait from field data. Most previous studies of recruitment have relied on estimation methods that may suffer from some biases, such as measuring the age distribution of firsttime breeders without correcting for variations in survival or capture probabilities among cohorts or time (e.g., MacInnes and Dunn 1988, Moser and Rusch 1989, Thompson et al. 1994, Schmutz 2000). Therefore, an individual that is observed breeding for the first time may have bred previously. Recently, robust mark-recapture methods have been developed to obtain unbiased estimates of age at first breeding (Clobert et al. 1994, Pradel 1996, Pradel and Lebreton 1999, Schwarz and Arnason 2000), but only a few studies have made use of these new methods (Pradel et al. 1997, Cooch et al. 1999b, Prévot-Julliard et al. 2001, Sedinger et al. 2001, Tavecchia et al. 2001).

We used a method that has been developed only recently and that, to our knowledge, has never been applied to field data. This method, described in Pradel and Lebreton (1999), is a particular case of a multistate mark-recapture model (Brownie et al. 1993, Nichols et al. 1994) with two states, including one that is nonobservable (e.g., when nonbreeders cannot be captured on the breeding grounds; see also Lebreton et al. 1999). With this method, data from individuals of known age (i.e., marked as young) are used to estimate juvenile survival and age-specific probabilities of becoming a breeder, whereas data from individuals marked as adults (i.e., of unknown age) are used to estimate adult (breeder) survival and capture probabilities. Including data from the latter group increases the precision of adult parameter estimates. When following only a single cohort, age and time are confounded, but by treating many cohorts simultaneously, one can separate age and time effects on recruitment probabilities. This method also has the advantage of allowing the separate esti- mation of juvenile survival and the proportion of individuals alive that enter the breeding population at a given age. An additional advantage of the multistate method is the possibility of assessing the effects of external and individual covariates on recruitment parameters pertaining to different cohorts.

We examined the influence of environmental conditions in early life (cohort median hatch date and within-cohort relative hatch date) and at breeding (snow cover at the onset of laying and lemming abundance) on recruitment in Greater Snow Geese (Chen caerulescens atlantica), hereafter GSG. This species is a good model for testing this multistate approach because it is relatively long-lived, it shows delayed maturity (females start reproducing at age $2 \mathrm{yr}$ or later), and it breeds in a stochastic environment where variations in weather and predation risk may lead to occasional skips of breeding. The multistate approach is especially well suited for sampling schemes in which nonbreeding individuals elude capture while many captured birds are of unknown age every year, a situation found in many field situations such as ours. In geese, females exhibit a high degree of natal philopatry, whereas males have high dispersal rates (Rohwer and Anderson 1988), so we analyzed data from females only.

\section{Methods}

\section{Study location and data set}

The study was conducted on the southwest plain of Bylot Island $\left(73^{\circ} 08^{\prime} \mathrm{N}, 80^{\circ} 00^{\prime} \mathrm{W}\right)$, Sirmilik National Park, Nunavut Territory, Canada. This area supports the largest nesting colony of GSG (55000 breeders in 1993 ), representing $\sim 15 \%$ of the world breeding population (Reed et al. 1998). From 1990 to 2000, extensive nest searches were conducted during the egg-laying and early-incubation periods. Nests were revisited at hatch and goslings were marked with individually coded web tags before they left the nest (for details, see Lepage et al. 2000).

Molting adult geese and their offspring were captured shortly before fledging in mass banding drives (Menu et al. 2001). Because nonbreeders or failed breeders leave the island to molt or have regained flight capacity when banding occurs, only adults that have bred successfully are caught (Reed et al. 2003). Upon capture, goslings and adults were sexed by cloacal examination and were marked with individually coded metal USFWS leg bands. A random sample of adult females was also fitted with individually coded plastic neck bands (Menu et al. 2000). Most goslings were measured and weighed (for details, see Lepage et al. 1998). Goslings were checked for the presence of web tags and adults were checked for neck bands, bands, and web tags.

Our data set thus consisted of the initial capture and all subsequent recaptures of females of known age (i.e., marked as goslings in banding drives) for which we 
had ninth primary wing feather measurements on initial capture. These females were classified as nonbreeders (NB) from initial capture until they were recruited into the breeding population. We also used data from females caught initially as adult breeders (B), i.e., of unknown age. Because there is evidence that the breeding propensity of adult females fitted with a neck band is reduced (Menu et al. 2000; E. T. Reed and G. Gauthier, unpublished data), we excluded these females from the data set. If a neck band was fitted to a female that had previously been marked with a metal leg band only, all subsequent recaptures were deleted by considering this individual as lost on capture. In a similar way, females that lost their neck bands were included in the data set of breeders, by considering their first capture without a neck band as their initial capture event. In this way, a maximum amount of information was kept while avoiding the biases due to heterogeneity in capture rates.

\section{Environmental covariates}

We examined four covariates representing environmental conditions encountered in early life and at the time of breeding (one individual and three group covariates).

Median nest hatching date.-Nest hatching date was directly recorded or estimated for every nest that hatched at least one young in the sample of nests followed by field crews. Hatch date was defined as the date at which at least half of the brood had hatched. Hatching was synchronized (usually $<24 \mathrm{~h}$ ) within a clutch. Median hatch date was calculated to obtain a population estimate.

Individual hatch date of marked goslings.-Individual hatch date of goslings web-tagged in the nest and captured during banding ( $\sim 4 \%$ of captured goslings) was known. For the other goslings, we estimated their age from the annual linear relationships between the age of web-tagged goslings and the length of their ninth primary. Because there is little sexual dimorphism at that age, males and females were combined in these relationships. Primary length is a good predictor of age before fledging because its growth is less sensitive to environmental conditions than are other morphometrics (Lepage et al. 1998, Cooch et al. 1999a). Individual hatch dates were transformed into relative values with respect to median annual hatch date.

Snow cover.-A qualitative assessment of total snow cover in the main valley of Bylot Island was made during the snow melt period every year from a vantage point near the base camp. We used snow cover estimated on 5 June, which is just before the peak of nest initiation (average across years, 11 June; annual range, 6-20 June), as an annual index of spring phenology. Preliminary analyses showed that snow cover on 5 June was highly correlated with mean air temperature during the pre-laying and laying periods (25 May-15 June). We chose snow cover over air temperature in our anal- yses because it is more indicative of the availability of nest sites and food at the onset of egg laying.

Lemming abundance.-We used a categorical variable to describe annual lemming (brown lemming, Lemmus sibiricus; and collared lemming, Dicrostonyx groenlandicus) abundance on Bylot Island. Each year since 1993, intensive trapping of lemmings or winter nest surveys have been conducted at our study site (Bêty et al. 2001). Presence of Snowy Owl (Nyctea scandiaca) nests is another index of lemming abundance because they only occur during peak lemming years in our study area. We categorized lemming abundance as high when abundance reached a peak (every 3-4 yr in our area) and Snowy Owls were breeding, moderate when lemming abundance was intermediate, and low when lemming populations crashed.

\section{Statistical method}

Data were analyzed using a particular case of multistate model with two states (NB and B) of which one (NB) was non-observable except at birth (Lebreton et al. 1999, Pradel and Lebreton 1999). Three kinds of parameters can be estimated with these models: apparent survival probability $\Phi_{t}^{r}$, conditional transition probability $\Psi_{t}^{r s}$, and capture probability $p_{t}^{r}$ (Brownie et al. 1993, Nichols et al. 1994). Definitions are as follows: $\Phi_{t}^{r}$ is the probability that an individual in state $r$ at time $t$ survives until time $t+1$ (an apparent survival probability because we cannot differentiate between mortality and permanent emigration from the study area); $\Psi_{t}^{r s}$ is the probability that an individual in state $r$ at time $t$ is in state $s$ at time $t+1$, given that it survived from time $t$ to $t+1$; and $p_{t}^{r}$ is the probability that an individual is recaptured at time $t$ in state $r$, given that it is alive and present in the study area at time $t$.

These parameters can be conveniently summarized in matrices of transition, survival, and capture probabilities:

$$
\left(\begin{array}{ll}
\Psi_{i}^{\mathrm{NB}-\mathrm{NB}} & \Psi_{i}^{\mathrm{B}-\mathrm{NB}} \\
\Psi_{i}^{\mathrm{NB}-\mathrm{B}} & \Psi_{i}^{\mathrm{B}-\mathrm{B}}
\end{array}\right),\left(\begin{array}{c}
\Phi_{i}^{\mathrm{NB}} \\
\Phi_{i}^{\mathrm{B}}
\end{array}\right) \text {, and }\left(\begin{array}{c}
p_{i}^{\mathrm{NB}} \\
p_{i}^{\mathrm{B}}
\end{array}\right) .
$$

In the special case of recruitment analyses, transition probabilities are unidirectional, i.e., once an individual starts breeding, it remains a "breeder" for the rest of its life; thus, transition probabilities from B to NB are fixed at 0 . With the "nonbreeder" state being unobservable, capture probabilities of NB are also fixed at 0 . For this particular case, the matrices indexed by age $i$ (note that, for a given cohort, age and time are confounded) thus become

$$
\left(\begin{array}{ccc}
1-a_{i} & 0 \\
a_{i} & 1
\end{array}\right),\left(\begin{array}{c}
\Phi_{i} \\
\Phi_{i}
\end{array}\right), \text { and }\left(\begin{array}{l}
0 \\
p_{i}
\end{array}\right)
$$

where $a_{i}$ is the probability that an individual of age $i$ that has not yet reproduced starts to breed (Pradel and Lebreton 1999), hereafter referred as probability of starting to breed. 
Starting assumptions.-A few assumptions need to be made with this model, some of which may be relaxed without leading to severe biases. The minimal assumptions under which this multistate model is valid are:

1) Breeders (B) and adult nonbreeders (NB) of the same age $i$ share the same survival probabilities (no survival costs of reproduction).

2) Experienced breeders do not emigrate temporarily from the study area. In many field situations, this assumption is synonymous with an adult breeding propensity of 1 . If breeding propensity $<1$, then the parameter $a_{i}$ will be relative to adult breeding propensity (as indexed by adult capture probabilities).

3) Age at which all individuals have been recruited into the breeding segment of the population (hereafter, age of full breeding) must be determined and the parameter $a_{i}$ must be fixed to 1 at that age. Nonbreeders have a zero capture probability, so individuals that are never recruited into the local breeding population cannot be discriminated from individuals that die or emigrate permanently before recruiting locally. The age at which full breeding is attained can be tested formally in the model selection procedure.

Other assumptions, based on the biology of GSG and field considerations, were made. These assumptions reduced the number of parameters in our starting model, thus reducing parameter identifiability problems and the number of potential candidate models, allowing us to concentrate on models that address hypotheses relevant to the study of recruitment.

1) Probability of capture at age $1 \mathrm{yr}$ is 0 , because only breeders are caught. Studies in other species of geese have shown that minimum age of reproduction is $2 \mathrm{yr}$ (Cooch et al. 1999b). In the $11 \mathrm{yr}$ of our study, only two females out of 7541 marked as young were caught at age $1 \mathrm{yr}$. They were probably still associated with their parents, as some families remain intact for more than a year (E. T. Reed and G. Gauthier, unpublished data). These recaptures were deleted from the capture history record.

2) Juvenile survival is estimated over the age interval $0-2$ (where age $0=$ fledging) and survival after age 2 is equal to adult survival.

3) There are no age effects on adult survival, such that young adults ( $\geq$ age 2 ) are as likely to survive as older ones.

4) There are no age or experience effects on capture probabilities. Because a breeding failure or skipped breeding in geese often leads to temporary emigration, we must assume that age or experience does not influence breeding success or breeding effort.

We will discuss the consequences for parameter estimates when some of these assumptions are violated.

\section{Model selection}

Model notation followed Nichols et al. (1994). The factorial structure of a model was represented by sub- scripting probabilities of apparent survival, capture, and start of breeding at age $i\left(a_{i}\right)$. Relations among factors were indicated via standard linear models notation (McCullagh and Nelder 1989). We started by fitting model $\Phi_{\text {coh }}^{\mathrm{J}} \Phi_{t}^{\mathrm{A}} p_{t}^{\mathrm{B}} a_{\text {age(full a5)*coh. In this model, }}$ apparent survival of juveniles ( $\mathrm{J}$, age $0-2$ ) varies among cohorts (coh) (here, cohort is used for clarity, but cohort and time are confounded). We fixed survival probability between age 0 and age 1 at 1 , such that survival for age 1-2 was the product of survival probabilities for the first two years of life. Apparent survival and capture probabilities of adults (A, breeders or nonbreeders, $\geq$ age 2 ) varied over time $(t)$. The probability of starting to breed at age $i\left(a_{i}\right)$ varied among cohorts and age (age) between age 2 and age of full breeding (but was fixed at 0 between age 0 and 1 ; i.e., no female reproduces at age 1$)$, with an interaction term $(*)$. Age of full breeding $\left(a_{i}=1\right)$ was fixed at $5 \mathrm{yr}$ (full $\left.a_{5}\right)$.

There are no formal goodness-of-fit tests available for multistate mark-recapture models. However, one way of verifying whether our general model reasonably fits the data is to partition each state into independent groups and test each group separately with the goodness-of-fit (GOF) tests developed for the Cormack-Jolly-Seber model. Our study design allowed us to test the GOF of our general model only on the breeders' data, because nonbreeders are never captured. We used program U-Care (Choquet et al. 2001) to assess the fit of our general model. GOF tests in U-Care are the same as those of program RELEASE (Burnham et al. 1987), but they provide further directional $z$ tests for possible structural problem in the data (e.g., transient or trap effects). We calculated a variance inflation factor $(\hat{c})$ to account for overdispersion in our data as

$$
\hat{c}=\frac{\chi^{2}}{\mathrm{df}}
$$

where $\chi^{2}$ is the goodness-of-fit statistic for our global model and $\mathrm{df}$ is the degrees of freedom of the model. We then used a modification of Akaike's Information Criterion $\left(\mathrm{QAIC}_{\mathrm{c}}\right.$ ) for overdispersed count data (for details, see Burnham and Anderson 1998).

We used program MARK version 1.9 (White and Burnham 1999) for model selection. Group and individual covariates were tested through ultrastructural models and were directly included in the iterative process through the design matrix option in MARK. Covariates were fitted to the model by linear constraints (on a logit scale). To ensure proper parameter estimation, all covariates, excluding lemming abundance, were standardized as

$$
\frac{(X-\bar{X})}{\mathrm{SD}} .
$$

We tried to explain cohort effects on juvenile apparent survival and the probability of starting to breed with cohort-specific median hatch dates. We also con- 

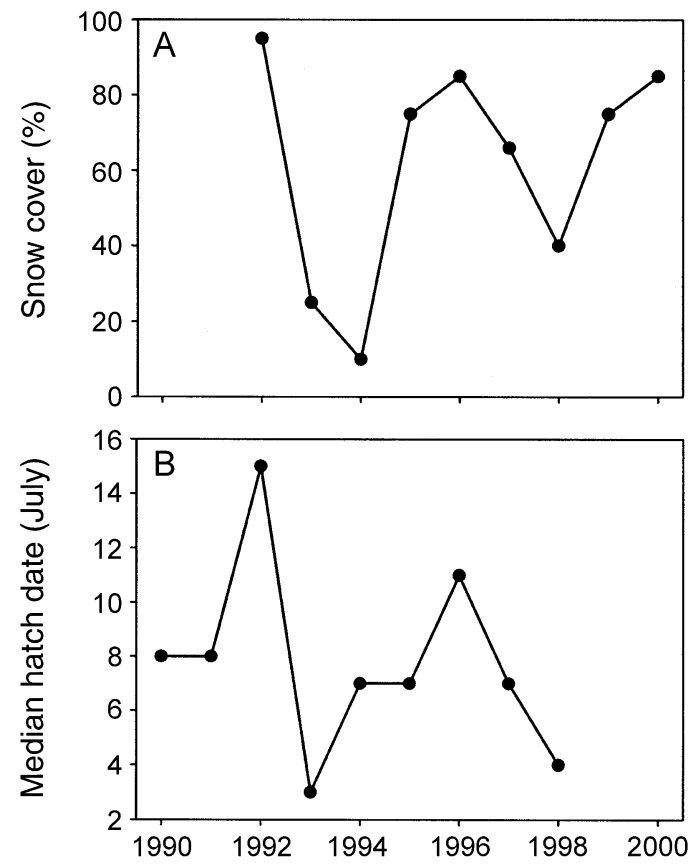

FIG. 1. (A) Percentage of snow cover on 5 June from 1992 to 2000 at our study site on Bylot Island, Canada, and (B) year-specific median hatch dates from Greater Snow Goose nests monitored between 1990 and 1998. Snow cover refers to conditions encountered in the year when birds first breed, whereas median hatch date represents conditions encountered at birth.

sidered the influence of relative hatch date on these two parameters. We examined the consequences of snow cover and lemming abundance on the probability of starting to breed, but not on survival, because these variables were most likely to affect breeding probability. Cohort median hatch date and individual relative hatch date referred to conditions encountered at birth, whereas snow cover and lemming abundance referred to conditions encountered at breeding. When the only difference between two models is a single covariate, a small value of $\Delta \mathrm{QAIC}_{\mathrm{c}}$ between these two models is not good evidence of an effect of the covariate. Rather, the confidence intervals around the beta estimates $(\beta$, slope of the linear relationship between the parameter and the covariate, or the difference among levels of a categorical covariate) provide useful evidence of an effect. We used this approach and concluded that covariates had an effect when their $95 \%$ confidence intervals did not include 0 . Main effects and biologically relevant interactions between parameters and covariates were fitted.

\section{RESUlts}

\section{Environmental covariates}

Snow cover on 5 June varied greatly from year to year, ranging from $10 \%$ to $95 \%$ (Fig. 1A). Mean snow cover over the period 1992-2000 was $62 \pm 30 \%$ (mean $\pm 1 \mathrm{SD}$ ). Peaks in the lemming cycle occurred in 1993, 1996, and 2000, with lows in 1995 and 1999; other years had a moderate abundance (Bêty et al. 2001). There was no lemming trapping in 1992, but we categorized that year as having moderate abundance, based on field observations of Lepage et al. (1996).

In total, 3173 nests were monitored between 1990 and 1998 (range 168-846 nests/yr). During this period, median hatch date ranged from 3 to 15 July (Fig. 1B). We captured a total of 557 goslings of known age between 1990 and 1998 (range 9-102 goslings/yr), from which we calculated regression coefficients between age and length of ninth primary feather (Table 1). The difference in age at capture between known-age goslings and those for which age was estimated was slight for most cohorts $(<1.6 \mathrm{~d}$ for seven of the nine cohorts; Table 1). Individual relative hatch dates varied from $10 \mathrm{~d}$ before the median to $14 \mathrm{~d}$ after (Fig. 2).

\section{Goodness of fit of the general model}

Between 1990 and 1998, we marked 6395 female goslings, of which 206 were recaptured as known-age breeders between 1992 and 2000. In addition, 1979

TABLE 1. Model parameters for age estimation of Greater Snow Goose (Chen caerulescens atlantica) goslings captured at banding based on ninth primary length, mean age of marked goslings at capture, and mean age of unmarked female goslings estimated by the model.

\begin{tabular}{|c|c|c|c|c|c|c|c|c|}
\hline \multirow[b]{2}{*}{ Year } & \multicolumn{6}{|c|}{ Marked young } & \multicolumn{2}{|c|}{ Unmarked females } \\
\hline & Intercept & Slope & MSE & $R^{2}$ & $n$ & $\begin{array}{c}\text { Age at } \\
\text { capture } \dagger(\mathrm{d})\end{array}$ & $n$ & $\begin{array}{l}\text { Estimated age } \\
\text { at capture } \dagger \text { (d) }\end{array}$ \\
\hline 1990 & 16.73 & 0.076 & 0.87 & 0.82 & 9 & $41.7 \pm 1.8$ & 75 & $38.8 \pm 3.0$ \\
\hline 1991末 & 18.98 & 0.111 & 1.80 & 0.73 & 17 & $39.4 \pm 3.3$ & 530 & $36.6 \pm 3.1$ \\
\hline 1992末 & 19.52 & 0.099 & 1.15 & 0.84 & 47 & $29.6 \pm 1.6$ & 392 & $29.2 \pm 2.4$ \\
\hline 1993末 & 22.81 & 0.099 & 1.75 & 0.63 & 102 & $40.2 \pm 2.8$ & 849 & $38.6 \pm 2.7$ \\
\hline 1994\$ & 27.62 & 0.071 & 1.69 & 0.72 & 62 & $36.1 \pm 3.2$ & 819 & $36.2 \pm 2.4$ \\
\hline $1995 \ddagger$ & 22.50 & 0.098 & 1.19 & 0.75 & 74 & $36.0 \pm 2.4$ & 1072 & $35.7 \pm 2.4$ \\
\hline $1996^{\circ}$ & 23.15 & 0.080 & 1.49 & 0.75 & 96 & $31.3 \pm 2.6$ & 834 & $32.0 \pm 3.2$ \\
\hline 1997 & 26.84 & 0.064 & 1.49 & 0.58 & 72 & $34.7 \pm 1.7$ & 1064 & $34.0 \pm 1.8$ \\
\hline 1998 & 25.17 & 0.085 & 1.6 & 0.77 & 78 & $36.9 \pm 2.9$ & 631 & $37.1 \pm 2.4$ \\
\hline
\end{tabular}

$\dagger$ Values are mean \pm 1 SE.

$\$$ Data are from Lepage et al. (1998). 


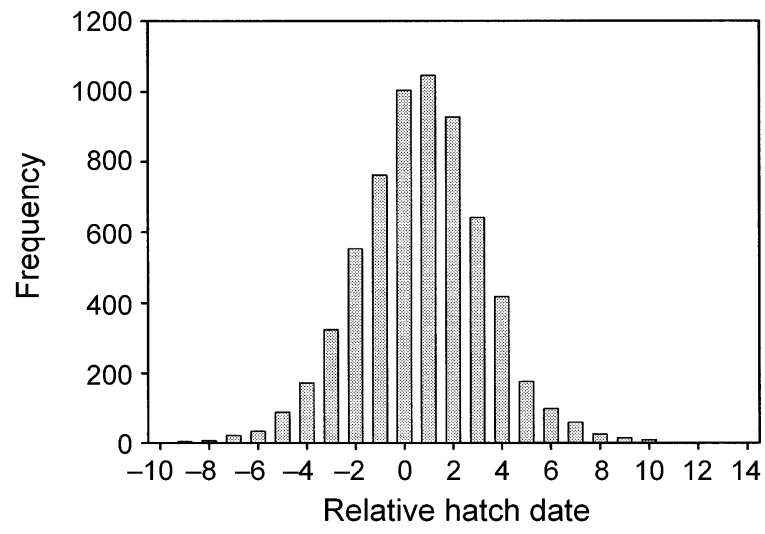

FIG. 2. Frequency distribution of relative hatch dates of all female goslings marked on Bylot Island, 1990-1998. Individual hatch dates are relative to the median hatch date for a given cohort. Hatch dates were estimated from the length of the ninth primary feather (see Table 1).

adult females of unknown age were initially captured as breeders between 1990 and 1999, and 276 were recaptured between 1991 and 2000 .

The GOF test of our general model, applied only to the breeder state, indicated a lack of fit $\left(\chi^{2}=75.42\right.$, $\mathrm{df}=45, P<0.01)$. There was a transient effect (Test3.Sr: $\chi^{2}=22.26$, df $=9, P<0.01$ ) and trap dependence in the form of trap shyness (Test2.Ct: $\chi^{2}$ $=18.02, \mathrm{df}=8, P=0.02)$. This lack of fit was driven by a few cells that had high $\chi^{2}$ values, and biological interpretation was not consistent among time periods (e.g., there was trap happiness in some time periods). The results from our GOF tests and the relatively small value of the variance inflation factor from the global test $(\hat{c}=1.66)$ were compatible with overdispersed count data. We therefore applied this value of the variance inflation factor for all subsequent model fitting.

\section{Adult survival and capture probabilities}

There was no detectable yearly variation in apparent survival of adults over the course of our study (Table 2). Apparent survival of adults was estimated at 0.84 (95\% CI: 0.77-0.90). Capture probabilities of breeders varied across years, but this variation could not be explained by environmental conditions (snow cover or lemming abundance; Table 2). Annual capture rates ranged from $0.02(0.00-0.18)$ to $0.08(0.06-0.12)$.

\section{Environmental and cohort effects on juvenile survival}

Juvenile apparent survival varied considerably among cohorts, but this variability could not be explained simply by a cohort's median hatch date (Table 2 ). In contrast, relative hatch date of individual females

TABLE 2. Selection among models of recruitment in female Greater Snow Geese. Models include probabilities of survival $(\Phi)$, capture $(p)$, and starting to breed $(a)$ and are ranked by their $\mathrm{QAIC}_{\mathrm{c}}$ value, with only the most relevant models being presented.

\begin{tabular}{|c|c|c|c|}
\hline Model number and name & $\Delta \mathrm{QAIC}_{\mathrm{c}}^{\dagger}$ & $w_{i} \neq$ & $\begin{array}{c}\text { No. } \\
\text { parameters }\end{array}$ \\
\hline 1) $\Phi_{\mathrm{coh}+\text { rel-hatch }}^{\mathrm{J}} \Phi^{\mathrm{A}} p_{t}^{\mathrm{B}} a_{\mathrm{age}(\mathrm{full} a 4)+\mathrm{Lem}}$ & 0.00 & 0.43 & 25 \\
\hline 2) $\Phi_{\text {coh+rel_hatch }}^{\mathrm{J}} \Phi^{\mathrm{A}} p_{t}^{\mathrm{B}} a_{\text {age(full } a 4)+ \text { snow }+ \text { Lem }}$ & 1.94 & 0.17 & 26 \\
\hline 3) $\Phi_{\text {coh+rel_hatch }}^{\mathrm{J}} \Phi^{\mathrm{A}} p_{t}^{\mathrm{B}} a_{\text {age(full a4) }}$ & 2.93 & 0.10 & 23 \\
\hline 4) $\Phi_{\text {coh+rel_hatch }}^{\mathrm{J}} \Phi^{\mathrm{A}} p_{t}^{\mathrm{B}} a_{\text {age(full } a 4)+ \text { rel_hatch }}$ & 3.40 & 0.08 & 24 \\
\hline 5) $\Phi_{\text {coh+rel_hatch }}^{\mathrm{J}} \Phi^{\mathrm{A}} p_{t}^{\mathrm{B}} a_{\mathrm{age}(\mathrm{full} a 4)+\text { med_hatch }}$ & 3.65 & 0.07 & 24 \\
\hline 6) $\Phi_{\mathrm{coh}+\text { rel-hatch }}^{\mathrm{J}} \Phi^{\mathrm{A}} p_{t}^{\mathrm{B}} a_{\mathrm{age}(\mathrm{full} a 4)+\text { snow }}$ & 3.90 & 0.06 & 24 \\
\hline 7) $\Phi_{\text {coh+rel_hatch }}^{\mathrm{J}} \Phi^{\mathrm{A}} p_{t}^{\mathrm{B}} a_{\text {age(full } a 4)+ \text { med_hatch+rel_hatch }}$ & 4.53 & 0.04 & 25 \\
\hline 8) $\Phi_{\text {coh+rel_hatch }}^{\mathrm{J}} \Phi^{\mathrm{A}} p_{t}^{\mathrm{B}} a_{\text {age(full } a 4)+ \text { med_hatch+rel_hatch+snow+Lem }}$ & 5.92 & 0.02 & 28 \\
\hline 9) $\Phi_{\text {coh+rel_hatch }}^{\mathrm{J}} \Phi^{\mathrm{A}} p_{t}^{\mathrm{B}} a_{\text {age(full } a 4)+ \text { med_hatch+rel_hatch+snow }}$ & 6.53 & 0.02 & 26 \\
\hline 10) $\Phi_{\text {coh }}^{\mathrm{J}} \Phi^{\mathrm{A}} p_{t}^{\mathrm{B}} a_{\text {age(full } a 4)+ \text { med_hatch+rel_hatch }}$ & 14.62 & 0.00 & 24 \\
\hline 11) $\Phi_{\text {coh+rel_hatch }}^{\mathrm{J}} \Phi^{\mathrm{A}} p_{t}^{\mathrm{B}} a_{\text {age(full } a 4)+\mathrm{coh}}$ & 18.12 & 0.00 & 32 \\
\hline 12) $\Phi_{\text {coh }}^{\mathrm{J}} \Phi^{\mathrm{A}} p_{t}^{\mathrm{B}} a_{\text {age(full } a 4)}$ & 22.36 & 0.00 & 22 \\
\hline 13) $\Phi_{\text {med_hatch+rel_hatch }}^{\mathrm{J}} \Phi^{\mathrm{A}} p_{t}^{\mathrm{B}} a_{\text {age(full } a 4)}$ & 24.60 & 0.00 & 16 \\
\hline 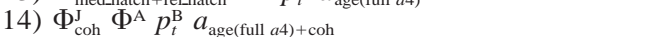 & 34.15 & 0.00 & 30 \\
\hline 15) $\Phi_{\mathrm{coh}}^{\mathrm{J}} \Phi^{\mathrm{A}} p_{t}^{\mathrm{B}} a_{\mathrm{age}(\mathrm{full} a 4){ }^{*} \mathrm{coh}}$ & 42.99 & 0.00 & 37 \\
\hline 16) $\Phi_{\mathrm{coh}}^{\mathrm{J}} \Phi^{\mathrm{A}} p_{t}^{\mathrm{B}} a_{\mathrm{age}(\text { full } a 5) *_{\mathrm{c}}}$ & 53.97 & 0.00 & 44 \\
\hline 17) $\Phi_{\text {coh }}^{\mathrm{J}} \Phi_{t}^{\mathrm{A}} p_{t}^{\mathrm{B}} a_{\text {age(full } a 5) *_{\mathrm{c}}}$ & 63.20 & 0.00 & 53 \\
\hline 18) $\Phi_{\text {coh }}^{\mathrm{J}} \Phi^{\mathrm{A}} p^{\mathrm{B}} a_{\text {age(full } a 5) * \mathrm{c}}$ & 76.32 & 0.00 & 35 \\
\hline
\end{tabular}

Notes: Terms are defined as follows: $\Phi^{\mathrm{J}}$, apparent survival of juvenile females between 0 and 2 years; $\Phi^{\mathrm{A}}$, apparent annual survival of adults; $p^{\mathrm{B}}$, adult breeder capture rate; $a$, probability that an individual that has not yet reproduced starts to breed; coh, cohort; $t$, time; age, age in years; med_hatch, cohort-specific median hatch date; rel_hatch, individual relative hatch date; lem, lemming density; snow, spring snow cover; full $a_{i}$, full breeding at age $i$ (i.e., the age at which all individuals have been recruited into the breeding segment of the population); + , additive model; *, model with interaction. Variables med_hatch and rel_hatch refer to conditions encountered at birth, whereas lem and snow refer to conditions in the year when birds first breed.

$\dagger$ Difference in $\mathrm{QAIC}_{\mathrm{c}}$ between the current model and the model with the lowest $\mathrm{QAIC}_{\mathrm{c}}$ value.

₹ QAIC $_{\text {c }}$ weight.

$\S$ The number of estimable parameters. 
FIG. 3. Relationship between juvenile apparent survival and relative hatch date of female Greater Snow Geese. Apparent survival is estimated from model 1 in Table 2 and covers the interval between age 0 (i.e., fledging) and $2 \mathrm{yr}$. The relationship is additive among cohorts and linear on a logit scale (slope: $\beta=-1.09,1 \mathrm{SE}$ $=0.29$ ).

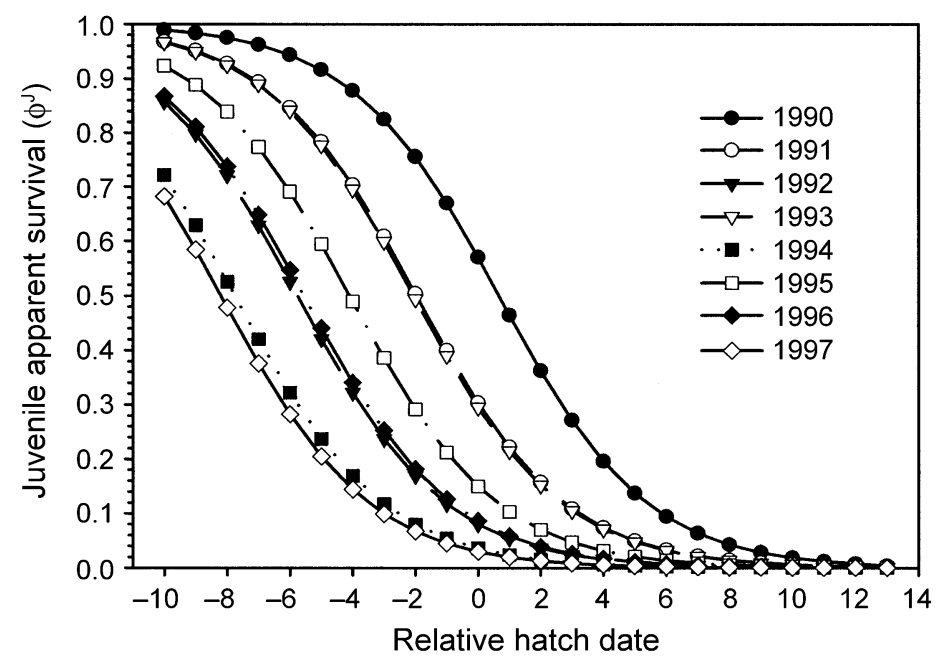

had a strong effect on their survival probabilities (an effect that was present in the nine top models in Table $2)$, with early-hatched females surviving to age $2 \mathrm{yr}$ in greater proportion than late-hatched ones $(\beta=-1.09$ [-1.65--0.52], model 1; Table 2). The absence of interaction between cohort and relative hatch date suggested that this effect was consistent across all cohorts, with survival probabilities declining rapidly in latehatched goslings (Fig. 3). Average cohort apparent survival of juveniles ranged from $0.76(0.25-0.97)$ to 0.09 (0.04-0.19) (Fig. 4). This parameter could not be estimated for the 1998 cohort because we only had one recapture occasion to assess it.

\section{Age of full breeding}

There was strong evidence for an age effect on recruitment (Table 2). We could reduce the age of full breeding (i.e., the age at which all females have started

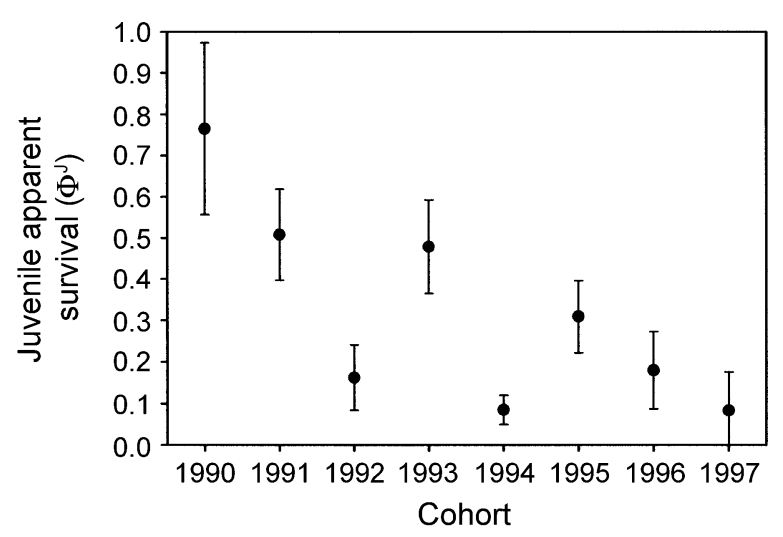

FIG. 4. Variation in apparent survival probabilities (mean across hatch dates for each cohort) of juvenile female Greater Snow Geese. Apparent survival (mean $\pm 1 \mathrm{SE}$; SE adjusted for extra-binomial variation, $\hat{c}=1.66$ ) is estimated from model 1 in Table 2 and covers the interval between age 0 (i.e., fledging) and 2 yr. Apparent survival for the 1998 cohort could not be estimated. breeding) to age $4 \mathrm{yr}$, but not further. Thus, some adult females had not started to breed at age 2 and 3 , but all of them had started by age 4 . The probability that a female with no breeding experience would start to breed at age 2 was consistently lower than at age 3 (Fig. 5). Average probabilities that surviving females would start to breed were estimated at $0.25(0.12-0.45)$ at age $2,0.57(0.20-0.87)$ at age 3 , and 1.00 at age 4 (derived from model 3, Table 2).

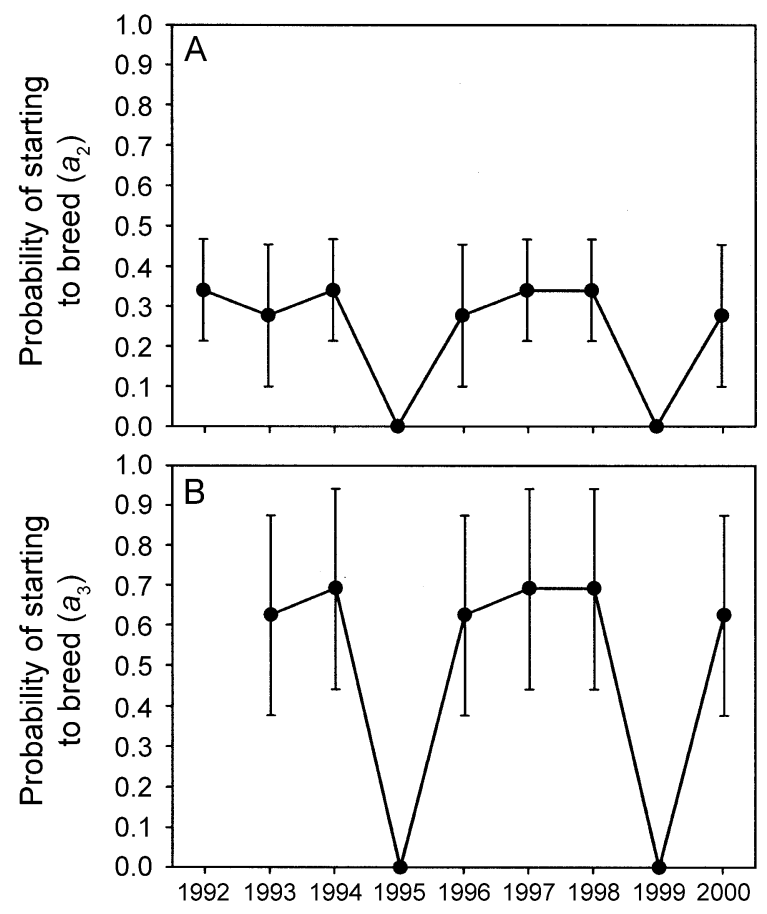

FIG. 5. Variation among cohorts in the probability that a Greater Snow Goose female with no breeding experience will start breeding at: (A) age 2 and (B) age 3. Estimates, derived from model 1 in Table 2 , are expressed as mean $\pm 1 \mathrm{SE}$ (SE adjusted for extra-binomial variation, $\hat{c}=1.66$ ). Years 1995 and 1999 were lemming crash years. 


\section{Environmental and cohort effects on age at first breeding}

The probability that a female with no breeding experience would start to breed was affected by lemming density. The cumulative $\mathrm{QAIC}_{\mathrm{c}}$ weight for models with a lemming effect was 0.62 (Table 2). Results from our best model indicated that $a_{i}$ was highly reduced in lemming crash years $(\beta=-14.96[-17.33--12.59])$, but similar at medium $(\beta=0.30[-1.70-2.29])$ and high lemming densities (Fig. 5). We had little evidence that the probability of starting to breed was affected by snow cover $(\beta=-0.18[-1.43-1.07]$; model 2$)$, relative hatch date $(\beta=-0.93[-3.03-1.16]$; model 4$)$, or cohort median hatch date $(\beta=0.63[-0.65-1.92]$; model 5, Table 2).

\section{DISCUSSION}

We showed that accession to reproduction was a gradual process in Greater Snow Geese, with the first females starting to breed at $2 \mathrm{yr}$ and the last ones at 4 yr. Among the environmental conditions studied, only lemming density had an effect on the probability that an individual would start to breed. Juvenile apparent survival was highly variable among cohorts, and was much more influenced by environmental conditions during early development than was the probability of starting to breed at a given age. Thus, juvenile survival seems to be the major factor responsible for variability in recruitment into the breeding population among different cohorts.

\section{Effect of age on local recruitment}

Delayed accession to reproduction is common among long-lived birds (Wooler and Coulson 1977, Pradel et al. 1997, Cooch et al. 1999b, Sedinger et al. 2001). Delayed reproduction has been linked to differences in individual quality (Forslund and Pärt 1995) and improved foraging or breeding skills (Recher and Recher 1969, Desrochers 1992). In geese, the high energetic demands of long migrations and reproduction (Ankney and MacInnes 1978, Gauthier et al. 1992, Choinière and Gauthier 1995) may constrain young, inexperienced individuals to delay reproduction. Lack of experience between young mates may also delay first reproduction because pairing in geese occurs in the second or third year of life, and breeding success increases with time since pairing (Owen et al. 1988, Black and Owen 1995).

Few studies have quantified age-specific breeding probability in birds by using robust mark-recapture methods (Cooch et al. 1999b, Anderson et al. 2001, Sedinger et al. 2001). It appears that probabilities of starting to breed in GSG are reduced at ages 2 and 3 $\mathrm{yr}$, in comparison to Black Brant (Branta bernicla nigricans) and Lesser Snow Geese (Chen c. caerulescens), but in all three species, most females have recruited at age $4 \mathrm{yr}$ (Cooch et al. 1999b, Sedinger et al.
2001). High population density could result in delayed accession to reproduction, but even though the GSG population more than doubled during our study (Reed et al. 1998), we failed to detect a consistent trend in the age of first reproduction. For similar evidence in Black Brant, see Sedinger et al. (2001). It appears more likely that the great unpredictability and stochasticity of the high-arctic environment, where delays in snow melt frequently deny access to nesting sites and prevent females from acquiring nutrients used for egg formation (Choinière and Gauthier 1995, Ganter and Cooke 1996), may result in reduced breeding effort (Prop and de Vries 1993). The long and energetically costly migration of GSG (Gauthier et al. 1992) may also constrain young birds in their ability to acquire sufficient nutrient reserves for successful breeding.

\section{Effect of conditions at time of breeding on recruitment}

We found that probabilities of starting to breed were considerably reduced when lemming densities were at their lowest during their 3-4 yr cycle, in comparison to years of high and medium lemming densities. Bêty et al. (2001) showed that annual nest failure of GSG on Bylot Island is negatively associated with lemming abundance and is generally highest in low lemming years. This high nest failure should mostly affect the probability of capture $(p)$, because most failed nesters leave the island before banding (Reed et al. 2003). However, if inexperienced birds suffer a higher nest predation rate than experienced breeders, this could negatively bias the probability of starting to breed $\left(a_{i}\right)$ in lemming crash years. Alternatively, disturbance by predators during the pre-laying and laying period may be sufficient to deter some females from breeding (e.g., Spaans et al. 1998). During lemming low years, predators such as arctic foxes (Alopex lagopus) switch to alternative prey and are more active at goose colonies (Bêty et al. 2002). Therefore, it is possible that lemming density indirectly influences a female goose's decision to delay reproduction until more favorable conditions are met.

We had no evidence that variable snow cover encountered at breeding, when females were 2 or $3 \mathrm{yr}$ of age, affected their probability of starting to breed. This suggests that, although breeding propensity and nesting success of adults is often reduced in years of late snow melt (Barry 1962, Prop and de Vries 1993, Skinner et al. 1998), birds at their first breeding attempt are not disproportionately affected by spring phenology.

\section{Effect of conditions in early life on recruitment}

Poor growth of late-hatched goslings has been reported in many goose species (Cooch et al. 1991, Larsson and Forslund 1991, Sedinger and Flint 1991), including GSG (Lepage et al. 1998). Manipulative experiments have demonstrated that variation in gosling growth is of environmental origin rather than a function 
of parental quality (Larsson and Forslund 1991, Lepage et al. 1999). These variations have fitness consequences, because body size at fledging affects postfledging survival (Owen and Black 1989, Menu 1998, Dawson and Clark 2000). Our results are consistent with these studies and show that survival declines sharply in latehatched goslings. Our apparent survival estimates for juveniles are well correlated with first-year survival estimates obtained from band recovery data for the cohorts 1990-1995 (Menu et al. 2002), except in 1990, when our estimate was possibly biased high because of low sample sizes. The juvenile survival estimate for the 1997 cohort also was probably biased low because all females from that cohort had not been recruited when our study ended (full breeding was attained only in 2001). Therefore, the apparent linear decline in juvenile survival over the course of our study may be due to biased survival estimates in 1990 and 1997 rather than being indicative of a density-dependent effect. Furthermore, Menu et al. (2002) found no evidence of density-dependent effects on other demographic parameters, despite the population increase.

In Black Brant, small body size negatively affects some reproductive parameters, possibly because small birds are less able to acquire sufficient body condition to breed (Sedinger et al. 1995). Because surviving latehatched goslings become adults of small body size (Cooch et al. 1991, Larsson and Forslund 1991), we expected a negative association between hatch date and the probability of starting to breed. However, our failure to detect such a relationship suggests that adult body size may have little effect on this demographic parameter.

An important assumption in our study is that length of ninth primary is an unbiased estimator of gosling age during the summer. Age estimated from body size measurements may nonetheless suffer from a positive bias in early-hatched goslings and a negative bias in late-hatched goslings, thus weakening our ability to detect seasonal effects on survival or probabilities of starting to breed (Cooch et al. 1999a). This bias is due to delays in the age of emergence of the ninth primary in late-hatched goslings (Lindohlm et al. 1994). By using year-specific models to estimate gosling age, we at least controlled for interannual differences in ninth primary growth.

\section{Survival, age at first breeding, and population dynamics}

Our results suggest that annual differences in accession to reproduction at 2 and especially $3 \mathrm{yr}$ of age are relatively small, except in low lemming years. This contrasts with juvenile survival, which varied considerably among cohorts. Prospective analyses of GSG population dynamics indicated that adult survival had the greatest influence on population growth rate, whereas juvenile survival and recruitment had lower elasticities, and were thus potentially less influential than adult survival (Gauthier and Brault 1998; see also Tombre et al. 1998). However, some vital rates may have a greater impact on population growth rates under natural conditions than that estimated by their elasticities if they account for a larger proportion of variance in population growth rates (Gaillard et al. 1998, Caswell 2000, Cooch et al. 2001). Thus, juvenile survival may still play a dominant role in the population dynamics of this species because it varies considerably more, under natural conditions, than adult survival (Gauthier et al. 2001) and the probability of starting to breed at a given age.

\section{Model assumptions and validity}

The use of multistate mark-recapture models to study recruitment requires fixing the value of some parameters and some assumptions. Because the computation of $a_{i}$ is based on the frequencies of first-time breeders and nonbreeders (i.e., individuals of age $i$ that have not yet reproduced) in the population ( $a=$ firsttime breeders)/(nonbreeders + first-time breeders); Pradel and Lebreton 1999), estimates will be biased when either estimated frequency is biased.

First, we had to postulate that breeders and nonbreeders share the same survival probabilities, i.e., that there is no cost of reproduction. Early maturation can sometimes be costly in terms of reduced survival (Wooler and Coulson 1977, Pyle et al. 1997, Tavecchia et al. 2001), but other studies have found a positive correlation between breeding effort and survival (Cam et al. 1998, Annett and Pierotti 1999). Although Francis et al. (1992) found a trend for higher survival in nonbreeding geese compared to breeders, Gauthier et al. (2001) found no evidence for increased mortality of breeding females during the summer. Viallefont et al. (1995) showed that apparent survival of Lesser Snow Geese did not differ between females recruiting at age 2 vs. age 3. Tombre and Erikstad (1996) did not detect reduced survival in Barnacle Goose (Branta leucopsis) females that had their incubation period (and, hence, reproductive investment) extended. In GSG, survival of females that provide parental care to their offspring for $\geq 10$ mo may be reduced (E. T. Reed and G. Gauthier, unpublished manuscript; but see Black and Owen 1989), although few females provide care for such long periods (Gauthier and Tardif 1991). Our estimate of apparent adult survival $(0.84)$ is very similar to estimates of true adult survival of GSG ( 0.81 and 0.85 , Menu et al. [2000]; 0.83, Gauthier et al. [2001]), suggesting that our estimate was unbiased and that breeding philopatry was very strong.

We also had to postulate that there were no age effects on adult survival ( $\geq$ age 2 ). There is no evidence for age effects on survival in geese 2-15 yr old (Owen 1984, Francis et al. 1992). Thus, not taking age into consideration probably did not bias our adult survival estimates. A negative bias in survival would affect the 
estimation of nonbreeders of a given age and potentially would lead to a positive bias in $a_{i}$.

Perhaps a more serious problem in our analysis is the assumption of no temporary emigration from the study area. Temporary emigration is confounded with true capture probabilities in most mark-recapture studies. In our particular case, temporary emigration can be explained by skipping (i.e., an experienced breeder does not attempt to breed in a given year) or by nest failure (an unsuccessful female leaves the study site to molt or regains flight capacity before capture time). Because temporary emigration is not an option for firsttime breeders (they have to breed successfully to recruit), the assumption that capture parameters are the same for first-time and experienced breeders may not hold.

In Lesser Snow Geese, females are more likely to skip breeding in the year following their first reproduction if they recruit at a young age (Viallefont et al. 1995); even experienced breeders may occasionally skip a breeding season. Nest failures, which also result in temporary emigration in our study, could lead to similar problems. If nest success also varies between first-time and experienced breeders (e.g., Rockwell et al. 1993), then this difference will be additive to the skipping bias in capture probabilities. Because estimation of the parameter $a_{i}$ is conditional on adult capture probabilities, these effects may negatively bias age-specific probabilities of starting to breed, but reflect more precisely the probabilities of starting to breed with success.

Our assumption that there were no age or experience effects on capture probabilities thus may have introduced heterogeneity and led to some biases in our analysis. This may explain why our goodness-of-fit test detected the presence of transients and some heterogeneity in capture rates, although such effects are not unusual. The magnitude of these potential biases on parameter estimates and their effects on model selection are presently unknown. Unfortunately, all capturerecapture approaches available for the study of recruitment assume no temporary emigration. It may be possible to accommodate temporary emigration in these models by incorporating a breeding probability of $<1$ for experienced breeders. However, increasing the number of parameters in the models may lead to reduced precision of parameter estimates and to serious parameter identification problems due to overparametrization (Pradel and Lebreton 1999).

The impossibility of accounting for differences in capture probabilities between experienced and firsttime breeders is still a weakness of all capture-recapture approaches for the study of recruitment. Nevertheless, these methods represent an important advance when an exhaustive census of all individuals present on the study area is not possible, leading to capture rates $<1$. The multistate method allowed us to include data on individuals marked as adults (i.e., of unknown age), leading to greater precision in parameter estimation. This method should be particularly useful when the number of known-age individuals recaptured as adults is small due to low juvenile survival or adult capture probabilities. Furthermore, extension of the multistate approach to include information from other sources, such as band recovery data and capture of nonbreeders or failed breeders on molting sites, potentially could address most of the constraints and assumptions made in our study (for details, see Lebreton et al. 1999).

\section{ACKNOWLEDGMENTS}

Funding was provided by a Natural Sciences and Engineering Research Council of Canada (NSERC) grant to G. Gauthier, the Arctic Goose Joint Venture (Canadian Wildlife Service), the Fonds pour la Formation des Chercheurs et l'Aide à la Recherche (FCAR, Ministère de l'Éducation du Québec), and the Department of Indian and Northern Affairs Canada. The FCAR, la Fondation de l'Université Laval, the Centre d'Études Nordiques, the Dennis Raveling Scholarship Fund, and the Fonds Richard Bernard provided financial assistance to E.T. Reed. Logistic support was generously provided by the Polar Continental Shelf Project (PCSP, Natural Resources Canada). The Hunters and Trappers Association of Pond Inlet, Nunavut Territory, kindly provided assistance and support. Thanks to the many people who participated in the field work, particularly Austin Reed and Gérald Picard. E.T. Reed is grateful to the Centre d'Écologie Fonctionnelle et Évolutive of Montpellier for providing working space and assistance during the writing of this paper. Arnaud Béchet, Gary White, and one anonymous reviewer provided valuable comments on earlier drafts of this manuscript. This is contribution number 016-02 of PCSP.

\section{Literature Cited}

Anderson, M. G., M. S. Lindberg, and R. B. Emery. 2001. Probability of survival and breeding for juvenile female Canvasbacks. Journal of Wildlife Management 65:385397.

Ankney, C. D., and C. D. MacInnes. 1978. Nutrient reserves and reproductive performance of female Lesser Snow Geese. Auk 95:459-471.

Annett, C. A., and R. Pierotti. 1999. Long-term reproductive output in Western Gulls: consequences of alternate tactics in diet choice. Ecology 80:288-297.

Barry, T. W. 1962. Effects of late seasons on Atlantic Brant reproduction. Journal of Wildlife Management 26:19-26.

Bell, G. 1980. The costs of reproduction and their consequences. American Naturalist 116:45-76.

Bêty, J., G. Gauthier, J.-F. Giroux, and E. Korpimäki. 2001. Are goose nesting success and lemming cycles linked? Interplay between nest density and predators. Oikos 93:388400.

Bêty, J., G. Gauthier, E. Korpimäki, and J.-F. Giroux. 2002. Shared predators and indirect trophic interactions: lemming cycles and arctic-nesting geese. Journal of Animal Ecology 71:88-98.

Black, J. M., and M. Owen. 1989. Parent-offspring relationships in wintering Barnacle Geese. Animal Behaviour 37:187-198.

Black, J. M., and M. Owen. 1995. Reproductive performance and assortative pairing in relation to age in Barnacle Geese. Journal of Animal Ecology 64:234-244.

Boyce, M. S., and C. M. Perrins. 1987. Optimizing Great Tit clutch size in a fluctuating environment. Ecology 68:142153. 
Brownie, C., J. E. Hines, J. D. Nichols, K. H. Pollock, and J. B. Hestbeck. 1993. Capture-recapture studies for multiple strata including non-markovian transitions. Biometrics 49:1173-1187.

Burnham, K. P., and D. R. Anderson. 1998. Model selection and inference: a practical information-theoretic approach. Springer-Verlag, New York, New York, USA.

Burnham, K. P., G. C. White, C. Brownie, and K. H. Pollock. 1987. Design and analysis methods for fish survival experiments based on release-recapture. American Fisheries Society Monographs 5.

Cam, E., J. E. Hines, J.-Y. Monnat, J. D. Nichols, and E. Danchin. 1998. Are adult nonbreeders prudent parents? The Kittiwake model. Ecology 79:2917-2930.

Caswell, H. 2000. Prospective and retrospective perturbation analyses: their role in conservation Biology. Ecology $\mathbf{8 1}$ : 619-627.

Choinière, L., and G. Gauthier. 1995. Energetics of reproduction in female and male Greater Snow Geese. Oecologia 103:379-389

Choquet, R., A.-M. Reboulet, R. Pradel, and J.-D. Lebreton. 2001. U-care (Utilities-CApture-REcapture) user's guide Version 1.1. 〈ftp://ftp.cefe.cnrs-mop.fr/biom/Soft-CR〉

Clobert, J., J.-D. Lebreton, D. Allainé, and J.-M. Gaillard. 1994. The estimation of age-specific breeding probabilities from recaptures or resightings in vertebrate populations: II. Longitudinal models. Biometrics 50:375-387.

Cooch, E. G., A. Dzubin, and R. F. Rockwell. 1999a. Using body size to estimate gosling age. Journal of Field Ornithology 70:214-229.

Cooch, E. G., R. L. Jefferies, R. F. Rockwell, and F. Cooke. 1993. Environmental change and the cost of philopatry: an example in the Lesser Snow Goose. Oecologia 93:128138.

Cooch, E. G., D. B. Lank, A. Dzubin, R. F. Rockwell, and F. Cooke. 1991. Body size variation in Lesser Snow Geese: environmental plasticity in gosling growth rates. Ecology 72:503-512.

Cooch, E. G., D. B. Lank, R. F. Rockwell, and F. Cooke. $1999 b$. Body size and age of recruitment in Snow Geese Anser c. caerulescens. Bird Study 46S:112-119.

Cooch, E. G., R. F. Rockwell, and S. Brault. 2001. Retrospective analysis of demographic response to environmental change: a Lesser Snow Goose example. Ecological Monographs 71:377-400.

Cooke, F., C. S. Findlay, and R. F. Rockwell. 1984. Recruitment and the timing of reproduction in Lesser Snow Geese (Chen caerulescens caerulescens). Auk 101:451-458.

Curio, E. 1983. Why do young birds reproduce less well? Ibis 125:400-404.

Dawson, R. D., and R. G. Clark. 2000. Effects of hatching date and egg size on growth, recruitment, and adult size of Lesser Scaup. Condor 102:930-935.

Desrochers, A. 1992. Age related differences in reproduction by European Blackbirds: restraint or constraint? Ecology 73:1128-1131.

Forslund, P., and T. Pärt. 1995. Age and reproduction in birds-hypotheses and tests. Trends in Ecology and Evolution 10:374-378.

Francis, C. M., M. H. Richards, F. Cooke, and R. F. Rockwell. 1992. Changes in survival rates of Lesser Snow Geese with age and breeding status. Auk 109:731-747.

Gadgil, M., and W. H. Bossert. 1970. Life historical consequences of natural selection. American Naturalist 104 $1-24$.

Gaillard, J.-M., M. Festa-Bianchet, and N. G. Yoccoz. 1998 Population dynamics of large herbivores: variable recruitment with constant adult survival. Trends in Ecology and Evolution 13:58-63.
Ganter, B., and F. Cooke. 1996. Pre-incubation feeding activities and energy budgets of Snow Geese: can food on the breeding grounds influence fecundity? Oecologia 106: $153-165$.

Gauthier, G., and S. Brault. 1998. Population model of the Greater Snow Goose: projected impacts of reduction in survival on population growth rate. Pages 65-80 in B. D. J. Batt, editor. The Greater Snow Goose: report of the Arctic Goose Habitat Working Group. U.S. Fish and Wildlife Service, Washington, D.C., USA, and Canadian Wildlife Service, Ottawa, Ontario, Canada.

Gauthier, G., J.-F. Giroux, and J. Bédard. 1992. Dynamics of fat and protein reserves during winter and spring migration in Greater Snow Geese. Canadian Journal of Zoology 70: 2077-2087.

Gauthier, G., R. Pradel, S. Menu, and J.-D. Lebreton. 2001. Seasonal survival of Greater Snow Geese and effect of hunting under dependence in sighting probability. Ecology 82:3105-3119.

Gauthier, G., and J. Tardif. 1991. Female feeding and male vigilance during nesting in Greater Snow Geese. Condor 93:701-711.

Larsson, K., and P. Forslund. 1991. Environmentally induced morphological variation in the Barnacle Goose, Branta leucopsis. Behavioral Ecology 2:116-122.

Lebreton, J.-D., T. Almeras, and R. Pradel. 1999. Competing events, mixtures of information and multistratum recapture models. Bird Study 46S:39-46.

Lepage, D., A. Desrochers, and G. Gauthier. 1999. Seasonal decline of growth and fledging success in Snow Geese Anser caerulescens: an effect of date or parental quality? Journal of Avian Biology 30:72-78.

Lepage, D., G. Gauthier, and S. Menu. 2000. Reproductive consequences of egg-laying decisions in Snow Geese. Journal of Animal Ecology 69:414-427.

Lepage, D., G. Gauthier, and A. Reed. 1996. Breeding-site infidelity in Greater Snow geese: a consequence of constraints on laying date? Canadian Journal of Zoology 74: 1866-1875.

Lepage, D., G. Gauthier, and A. Reed. 1998. Seasonal variation in growth of Greater Snow Goose goslings: the role of food supply. Oecologia 114:226-235.

Lindohlm, A., G. Gauthier, and A. Desrochers. 1994. Effects of hatch date and food supply on gosling growth in arcticnesting Greater Snow Geese. Condor 96:898-908.

MacInnes, C. D., and E. H. Dunn. 1988. Estimating proportion of an age class nesting in Canada Geese. Journal of Wildlife Management 52:421-423.

McCullagh, P., and N. A. Nelder. 1989. Generalized linear models. Chapman and Hall, New York, New York, USA.

Menu, S. 1998. Survie de la Grande Oie des neiges: aspects méthodologiques et implications dans la dynamique de population. Dissertation. Université Laval, Sainte-Foy, Canada.

Menu, S., G. Gauthier, and A. Reed. 2001. Survival of juvenile Greater Snow Geese immediately after banding. Journal of Field Ornithology 72:282-290.

Menu, S., G. Gauthier, and A. Reed. 2002. Changes in survival rates and population dynamics of Greater Snow Geese over a 30-year period: implications for hunting regulations. Journal of Applied Ecology 39:91-102.

Menu, S., J. B. Hestbeck, G. Gauthier, and A. Reed. 2000. Effects of neck bands on survival of Greater Snow Geese. Journal of Wildlife Management 64:544-552.

Moser, T. J., and D. H. Rusch. 1989. Age-specific breeding rates of female interior Canada Geese. Journal of Wildlife Management 53:734-740.

Nichols, J. D., J. E. Hines, K. H. Pollock, R. L. Hinz, and W. A. Link. 1994. Estimating breeding proportions and 
testing hypotheses about costs of reproduction with capture-recapture data. Ecology 75:2052-2065.

Owen, M. 1984. Dynamics and age structure of an increasing goose population-the Svalbard Barnacle Goose Branta leucopsis. Norsk Polarinstitutt Skrifter 181:37-47.

Owen, M., and J. M. Black. 1989. Factors affecting the survival of Barnacle Geese on migration from the breeding grounds. Journal of Animal Ecology 58:603-617.

Owen, M., J. M. Black, and H. Liber. 1988. Pair bond duration and timing of its formation in Barnacle Geese (Branta leucopsis). Pages 23-38 in M. L. Weller, editor. Waterfowl in winter. University of Minnesota Press, Minneapolis, Minnesota, USA.

Porter, J. M., and J. C. Coulson. 1987. Long-term changes in recruitment to the breeding group, and the quality of recruits at a Kittiwake Rissa tridactyla colony. Journal of Animal Ecology 56:675-689.

Pradel, R. 1996. Utilization of capture-mark-recapture for the study of recruitment and population growth rate. Biometrics 52:703-709.

Pradel, R., A. R. Johnson, A. Viallefont, R. G. Nager, and F. Cézilly. 1997. Local recruitment in the Greater Flamingo: a new approach using capture-mark-recapture data. Ecology 78:1431-1445.

Pradel, R., and J.-D. Lebreton. 1999. Comparison of different approaches to the study of local recruitment of breeders. Bird Study 46S:74-81.

Prévot-Julliard, A.-C., R. Pradel, R. Julliard, V. Grosbois, and J.-D. Lebreton. 2001. Hatching date influences age at first reproduction in the Black-headed Gull. Oecologia 127:6268.

Prop, J., and J. de Vries. 1993. Impact of snow and food conditions on the reproductive performance of Barnacle Geese Branta leucopsis. Ornis Scandinavica 24:110-121.

Pyle, P., N. Nur, W. J. Sydeman, and S. D. Emslie. 1997. Cost of reproduction and the evolution of deferred breeding in the Western Gull. Behavioral Ecology 8:140-147.

Recher, H. F., and J. A. Recher. 1969. Comparative foraging efficiency of adult and immature Little Blue Heron (Florida caerulea). Animal Behaviour 17:320-322.

Reed, A., J.-F. Giroux, and G. Gauthier. 1998. Population size, productivity, harvest and distribution. Pages 5-31 in B. D. J. Batt, editor. The Greater Snow Goose: report of the Arctic Goose Habitat Working Group. U.S. Fish and Wildlife Service, Washington, D.C., USA, and Canadian Wildlife Service, Ottawa, Ontario, Canada.

Reed, E. T., J. Mainguy, J. Bêty, G. Gauthier, and J.-F. Giroux. 2003. Molt migration in relation to breeding success in Greater Snow Geese. Arctic 56, In press.

Rockwell, R. F., E. G. Cooch, C. B. Thompson, and F. Cooke. 1993. Age and reproductive success in female Lesser Snow Geese: experience, senescence and the cost of philopatry. Journal of Animal Ecology 62:323-333.

Rohwer, F. C., and M. G. Anderson. 1988. Female-biased philopatry, monogamy, and the timing of pair formation in migratory waterfowl. Current Ornithology 5:187-221.
Schmutz, J. A. 1993. Survival and pre-fledging body mass in juvenile Emperor Geese. Condor 95:222-225.

Schmutz, J. A. 2000. Age-specific breeding in Emperor Geese. Wilson Bulletin 112:261-263.

Schwarz, C. J., and A. N. Arnasson. 2000. Estimation of agespecific breeding probabilities from capture-recapture data. Biometrics 56:59-64.

Sedinger, J. S., and P. L. Flint. 1991. Growth rate is negatively correlated with hatch date in Black Brant. Ecology 72:496502 .

Sedinger, J. S., P. L. Flint, and M. S. Lindberg. 1995. Environmental influence on life-history traits: growth, survival, and fecundity in Black Brant (Branta bernicla). Ecology 76:2404-2414.

Sedinger, J. S., M. S. Lindberg, and N. D. Chelgren. 2001. Age-specific breeding probability in Black Brant: effects of population density. Journal of Animal Ecology 70:798807.

Skinner, W. R., R. L. Jefferies, T. J. Carleton, R. F. Rockwell, and K. F. Abraham. 1998. Prediction of reproductive success and failure in Lesser Snow Geese based on early season climatic variables. Global Change Biology 4:3-16.

Spaans, B., H. J. Blijleven, I. U. Popov, M. E. Rykhlokova, and B. S. Ebbinge. 1998. Dark-bellied Brent Geese Branta bernicla bernicla forego breeding when arctic foxes Alopex lagopus are present during nest initiation. Ardea 86:11-20.

Spear, L., and N. Nur. 1994. Brood size, hatching order and hatching date: effects on four life-history stages from hatching to recruitment in Western Gulls. Journal of Animal Ecology 63:283-298.

Tavecchia, G., R. Pradel, V. Boy, A. R. Johnson, and F. Cézilly. 2001. Sex- and age-related variation in survival and cost of first reproduction in Greater Flamingos. Ecology 82: $165-174$.

Thompson, P. S., D. Baines, J. C. Coulson, and G. Longrigg. 1994. Age at first breeding, philopatry and breeding sitefidelity in the Lapwing Vanellus vanellus. Ibis 136:474484.

Tombre, I. M., J. M. Black, and M. J. J. E. Loonen. 1998. Critical components in the dynamics of a Barnacle Goose colony: a sensitivity analysis. Pages 81-89 in F. Mehlum, J. M. Black, and J. Madsen, editors. Research on Arctic geese. Proceedings of the Svalbrad Goose Symposium. Oslo, Norway, 23-26 September 1997. Norsk Polarinstitutt Skrifter 200.

Tombre, I. M., and K. E. Erikstad. 1996. An experimental study of incubation effort in high-Arctic Barnacle Geese. Journal of Animal Ecology 65:325-331.

Verboven, N., and M. E. Visser. 1998. Seasonal variation in local recruitment of Great Tits: the importance of being early. Oikos 81:511-524.

Viallefont, A., F. Cooke, and J.-D. Lebreton. 1995. Agespecific costs of first-time breeding. Auk 112:67-76.

White, G. C., and K. P. Burnham. 1999. Program MARK: survival estimation from populations of marked animals. Bird Study 46S: $120-139$.

Wooler, R. D., and J. C. Coulson. 1977. Factors affecting age of first breeding in the Kittiwake. Ibis 119:339-349. 